CERN-PPE / 96-35

CERN, February 9th, 1996

\title{
Cerium doped heavy metal fluoride glasses, a possible alternative for electromagnetic calorimetry
}

\author{
E. Auffray ${ }^{1}$, D. Bouttet ${ }^{2}$, I. Dafinei $^{3}$, J. Fay $^{4}$, P. Lecoq $^{1}$, J.A. Mares $^{5}$,

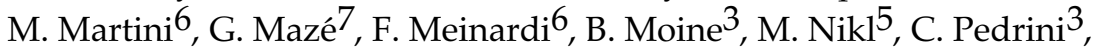 \\ M.Poulain 7 , M. Schneegans 8 , S. Tavernier ${ }^{9}$, A. Vedda 6
}

\begin{abstract}
The article is an overview of the research activity performed in the framework of the Crystal Clear Collaboration to produce scintillating glasses. The manufacturing of heavy metal fluoride glasses doped with $\mathrm{Ce}^{3+}$ is discussed. The luminescence and scintillation characteristics as well as the radiation hardness properties are extensively studied in the case of $\mathrm{Ce}$ doped fluorohafnate, found to be the most convenient glass scintillator for high energy physics applications.
\end{abstract}

This work was performed in the framework of The Crystal Clear Collaboration (CERN, RD18)

1 CERN Geneva, Switzerland

2 LPCM Lyon, CNRS and Université Claude Bernard, Villeurbanne, France

3 CERN Geneva, Switzerland, on leave from IFA Bucharest, Romania

4 IPN Lyon, IN2P3-CNRS and Université Claude Bernard, Villeurbanne, France

${ }^{5}$ Institute of Physics, Praha, Czech Repbublic

6 University of Milan, Dpt. of Physics, Milan, Italy

7 Le Verre Fluoré, F - 35770 Vern/Seiche, Bretagne

8 LAPP, IN2P3-CNRS, Annecy-le-Vieux, France

9 VUB, Vrije Universiteit Brussels, Belgium 


\section{Introduction}

The successful use of high precision electromagnetic calorimeters in high energy physics (HEP) experiments as well as the continuously increasing number of other applications in nuclear physics, in astrophysics, medical imaging and industry, triggered a spectacular development of the research for new heavy scintillating crystals and glasses [1, 2, 3]. Scintillating glasses can be cast in any shape and in a much shorter time than crystals. They are potentially more homogeneous than crystals and they present large possibilities for compositional improvements whereas in crystals improvements in light yield and radiation hardness can often be achieved only by increasing the purity of the crystal. The main drawback of scintillating glasses are their relatively low light yield and poor radiation hardness, even if the latter can be compensated by optical or thermal bleaching.

Several compositions of Heavy Metal Fluoride Glasses (HMFG) were studied by the Crystal Clear collaboration [4] and the Ce doped fluorohafnate glass (HFG) was finally selected as the most convenient scintillation material [5]. The main properties of a typical HFG:Ce glass are given in Table 1. It is the aim of this paper to report on the extensive investigations of HFG:Ce glass luminescence and scintillation characteristics as well as on the radiation hardness properties. In the text, Aluminate, Hafnate and Zirconate fluoride glass samples are named respectively AFG, HFG and ZFG. The sample identification is made in the frame of the identity number given to each crystal and glass sample in the database of the Crystal Clear Collaboration.

\section{Material study}

All glass samples studied in our work were produced by the company "Le Verre Fluoré" in France. High density and light yield, fast scintillation decay and a good radiation hardness are some of the main characteristics requested for a good scintillator to be used in HEP experiments. Fluoride glass as a host material with trivalent cerium as an activator is a very promising scintillator even though a good choice of the composition of HMFG for electromagnetic calorimetry is a compromise between various and often conflicting requirements.

\subsection{Manufacturing of Heavy Metal Fluoride Glasses doped with $\mathrm{Ce}^{3+}$}

Heavy Metal Fluoride Glasses are synthesised by melting a mixture of fluorides. The appropriate amounts of fluorides are mixed with ammonium hydrogen difluoride $\left(\mathrm{NH}_{4} \mathrm{FHF}\right)$ and then heated and melted in a crucible made of gold, platinum or vitreous carbon.

When pure fluorides are used, $10 \%$ of $\mathrm{NH}_{4} \mathrm{FHF}$ is added in order to remove the water adsorbed in the fluoride powders. Instead of pure fluorides, one can start with high purity oxides. In that case, the ammonium hydrogen difluoride serves to convert the oxides into fluorides. An excess of $50 \% \mathrm{NH}_{4} \mathrm{FHF}$ with respect to the stoechiometric proportions is necessary to complete the conversion. The mixture is heated up to $350^{\circ} \mathrm{C}$ for 1 to 3 hours depending on the proportion of oxides in the starting materials and the weight of the batch. The temperature of the batch is then raised up to the melting point and further fined at higher temperature. During the fining step the melt is homogenised and the reduced species formed during the treatment with ammonium bifluoride are oxidised. For that purpose a dry and 
oxidising atmosphere is maintained above the melt during the time of the process. After cooling, the melt is poured into brass moulds which have been previously heated around $250^{\circ} \mathrm{C}$. The glass blanks are then annealed around the glass transition temperature $\left(300^{\circ} \mathrm{C}\right)$.

Table 1. Physical properties of typical 5\% Ce doped fluorohafnate glass

\begin{tabular}{|c|c|c|}
\hline Radiation length & $(\mathrm{cm})$ & 1.6 \\
\hline Molière radius & $(\mathrm{cm})$ & 2.8 \\
\hline Specific mass & $\left(\mathrm{g} / \mathrm{cm}^{3}\right)$ & 5.95 \\
\hline Light yield & (photons / MeV) & 150 \\
\hline Decay time (short) & (ns) & 8 \\
\hline (long) & (ns) & 25 \\
\hline Emission peak & $(\mathrm{nm})$ & 325 \\
\hline $\begin{array}{l}\text { Temperature depenc } \\
\text { of light yield }\end{array}$ & $\left(\% /{ }^{\circ} \mathrm{C}\right)$ & -0.37 \\
\hline $\begin{array}{l}\text { Index of refraction } \\
\text { Radiation hardness }\end{array}$ & $\begin{array}{l}(\text { for } \lambda=587.6 \mathrm{~nm}) \\
(\mathrm{Gy})\end{array}$ & $\begin{array}{l}1.495 \\
100\end{array}$ \\
\hline $\begin{array}{l}\text { Softening temperatu } \\
\text { Hygroscopicity }\end{array}$ & $\left({ }^{\circ} \mathrm{C}\right)$ & $\begin{array}{l}\cong 380 \\
\text { No }\end{array}$ \\
\hline
\end{tabular}

The compositions of HFMG are based on the following fluorides: $\mathrm{ZrF}_{4}, \mathrm{BaF}_{2}$, $\mathrm{NaF}, \mathrm{LaF}_{3}, \mathrm{ThF}_{4}, \mathrm{YF}_{3}$ and $\mathrm{AlF}_{3}$ as a stabiliser. Since density is one of the major parameters to be taken into consideration for our application, Zirconium (Zr) was replaced by Hafnium (Hf) which is chemically very close and has similar glass forming ability. Replacing $\mathrm{ZrF}_{4}$ by $\mathrm{HfF}_{4}$ raises the specific mass from 4.5 up to $6 \mathrm{~g} / \mathrm{cm}^{3}$. Another drawback of $\mathrm{ZrF}_{4}$ is its bad influence on the radiation hardness of the material. Fig.1 gives the transmission spectrum of the main three types of HMFG undoped and 5\% Ce doped. It is obvious that given the necessity of a very good transmission in the $300 \mathrm{~nm}-400 \mathrm{~nm}$ region where the $\mathrm{Ce}^{3+}$ emission spectrum takes place, only HFG and ZFG should be considered for a Ce activated scintillation material. The fact that ZFG:Ce glass has a low density and an extremely low light yield reduces the choice to only one possibility, namely the HFG:Ce glass.

The basic HMFG glasses can accommodate up to 5\%, in mole, of rare earth elements. Proper adjustments of the composition allow that proportion to be doubled. Typical compositions and their properties are summarised in Table 2. Increasing the $\mathrm{CeF}_{3}$ concentration leads to an increased optical absorption in the $\mathrm{Ce}^{3+}$ emission region (fig.2). This effect is harmful for the light yield of large HMFG ingots where the increased light production at higher Ce concentrations is balanced by the optical reabsorbtion. An optimal $\mathrm{CeF}_{3}$ concentration of $5 \%$ was chosen for the HFG glass.

\subsection{Large size Ce-doped Hafnium Fluoride glass pieces of optical quality}

Fluoride melts have to be cooled at rather fast rate. This is due to the fact that the vitreous domains in HMF mixtures are narrow. Small differences in the composition can step up dramatically the rate of crystallisation during the cooling 
between the melting temperature and the glass transition temperature. Conversely, the stability of the glass can be significantly improved (i.e. its critical cooling rate decreased) by small changes in the composition. On the other hand, for a given composition and dimension, the rate at which the heat is evacuated is determined by the difference between the temperatures of the melt and of the mould and by the efficiency of the heat transfer to the mould. To some extent, these parameters can be optimised in order to enlarge the size of the glass pieces of optical quality, which is

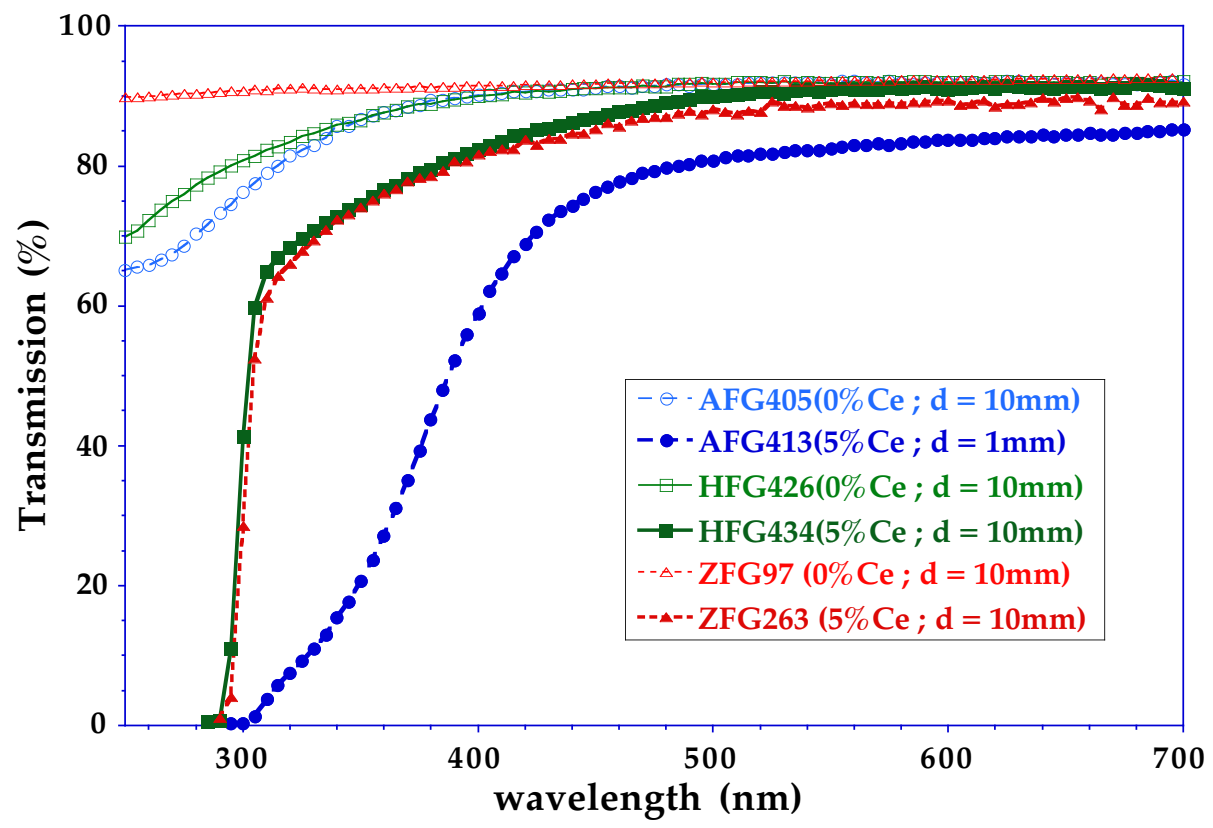

Fig. 1 Transmission spectra of different HMFG (doping level and sample thickness are given in parenthesis; note the $1 \mathrm{~mm}$ thickness of the AFG:Ce sample)

Table 2

Compositions and properties of Heavy Metal Fluoride Glasses (HMFG)

\begin{tabular}{|c|c|c|c|c|c|c|c|c|c|c|c|}
\hline Glass & $\begin{array}{l}\text { density } \\
\left(\mathrm{g} / \mathrm{cm}^{3}\right)\end{array}$ & $\begin{array}{c}\mathrm{T}_{\mathrm{g}}-\mathrm{T}_{\mathbf{m}} \\
\left({ }^{\circ} \mathrm{C}\right)\end{array}$ & $\begin{array}{c}\alpha \times 10^{6} \\
\left(1 /{ }^{\circ} \mathrm{C}\right)\end{array}$ & $\begin{array}{l}\text { refr. } \\
\text { index }\end{array}$ & $\begin{array}{l}\mathrm{AlF}_{3} \\
(\%)\end{array}$ & $\begin{array}{l}\mathrm{BaF}_{2} \\
(\%)\end{array}$ & $\begin{array}{l}\mathrm{ThF}_{4} \\
(\%)\end{array}$ & $\begin{array}{l}\mathrm{YF}_{3} \\
(\%)\end{array}$ & $\begin{array}{l}\mathrm{NaF} \\
(\%)\end{array}$ & $\begin{array}{l}\mathrm{HfF}_{4} \\
(\%)\end{array}$ & $\begin{array}{l}\mathrm{ZrF}_{4} \\
(\%)\end{array}$ \\
\hline ZFG & 4.50 & 295-550 & 18 & 1.50 & 2 & 28 & - & 2 & 12 & - & $>50$ \\
\hline HFG & 5.95 & $310-570$ & 17 & 1.49 & 2 & 28 & - & 2 & 12 & $>50$ & - \\
\hline AFG & 5.75 & $400-730$ & 15 & 1.50 & $>28$ & 28 & 20 & 20 & - & - & - \\
\hline
\end{tabular}

$\mathrm{T}_{\mathrm{g}}$ : glass transition temperature $; \alpha$ : thermal expansion coefficient $\mathrm{T}_{\mathrm{m}}$ : melting temperature

one of the key issues for the use of fluoride glasses as scintillating materials. For a given set of conditions, the largest dimension is reached when there is a volume element in the melt that is cooled at a rate equal to the critical cooling rate associated with its composition. In the case of a spherical ball, uniformly cooled, the last volume element that reaches the glass transition temperature is located at the centre. As long 
as the cooling rate of this volume remains faster or equal to the critical cooling rate, the entire volume of the ball is glassy. It is clear that the cooling rate decreases for balls of larger diameters and therefore there is a critical diameter above which the ball crystallises in part or entirely.

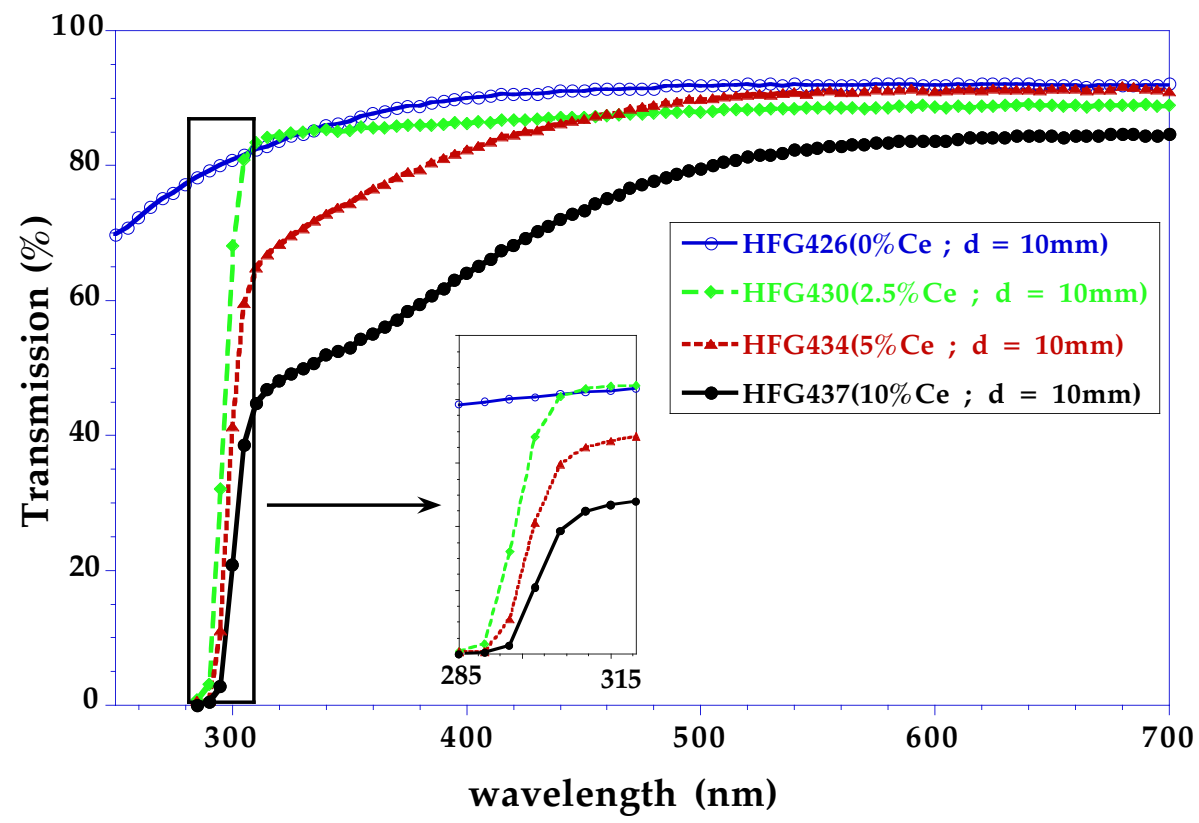

Fig. 2 Dependence of transmission spectra of HFG for different Ce doping levels (doping level and sample thickness are given in parenthesis)

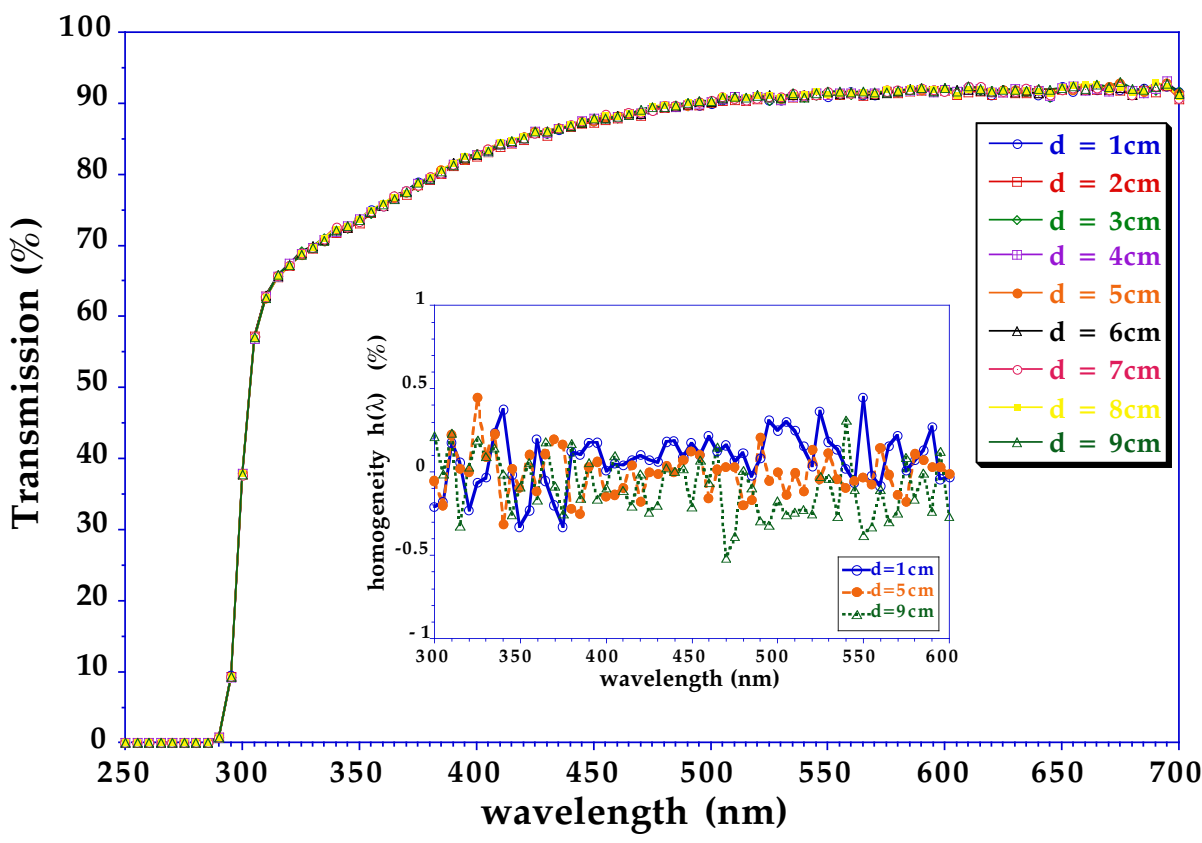

Fig. 3 Optical transmission of a hafnate glass (HFG794, $\mathrm{L}=94.5 \mathrm{~mm})$ measured transversally $(1=14.2 \mathrm{~cm})$ at different positions along the ingot 
It is a common observation that the risk of devitrification is much higher for glasses of high chemical purity than for glasses made out of less pure raw material. This is also true for Hafnium Fluoride glasses. In spite of the difficulty inherent to the use of high purity materials, the glass pieces produced for this study were made from $5 \mathrm{~N}$ purity materials.

Table 3

Dimensions (mm) and optical quality (O.Q.) of 5\% Ce-doped Hafnium Fluoride glass pieces

\begin{tabular}{|c|c|c|c|c|c|}
\hline 1992 & O.Q. & $\mathbf{1 9 9 3}$ & O.Q. & $\mathbf{1 9 9 4}$ & O.Q. \\
\hline $5 \times 5 \times 5$ & $\mathrm{P}$ & $10 \times 10 \times 10$ & $\mathrm{P}$ & $15 \times 15 \times 100$ & $\mathrm{E}$ \\
\hline & & $10 \times 10 \times 50$ & $\mathrm{E}$ & $15 \times 25 \times 138$ & $\mathrm{G}$ \\
\hline & & \multicolumn{4}{|c|}{$\mathrm{E}=$ Excellent } \\
\hline
\end{tabular}

The first Ce-doped fluoride glass samples were of poor optical quality although they contained only $1 \% \mathrm{Ce}^{3+}$. Within 2 years time, the original volume was enlarged 600 times, the initial concentration of Ce was increased fivefold and the final pieces were of good optical quality. Table 3 indicates the evolution of the dimensions of the pieces which were produced in the course of this work. Fig.3 gives the optical transmission measured transversally along a $14 \mathrm{~cm}$ ingot of HFG:Ce glass. The transmission homogeneity $h_{d}(\lambda)$ is better than $0.5 \%$ in the whole $300 \mathrm{~nm}$ to $600 \mathrm{~nm}$ wavelength range. The homogeneity $\mathrm{h}_{\mathrm{d}}(\lambda)$ is defined as:

$$
h_{d}(\lambda)=100 \times \frac{\left|T_{\text {mean }}(\lambda)-T_{d}(\lambda)\right|}{T_{\text {mean }}(\lambda)}(\%)
$$

where:

$$
T_{\text {mean }}(\lambda)=\frac{\sum_{d} T_{d}(\lambda)}{n}
$$

and $T_{d}(\lambda)$ is the transversal transmission measured in $n$ equidistant points $d$

\section{Scintillation properties}

Photoluminescence and decay kinetics measurements have been performed using a Spectrofluorimeter 199S (Edinburgh Instrument) modified for low temperature measurements. Excitation and emission spectra are measured with $2.6 \mathrm{~nm}$ spectral resolution and corrected for the instrumental response to obtain the true physical characteristics of the samples studied. True decay time characteristics are obtained from the decay curves using deconvolution procedures allowing the extraction of the true parameters with an error of a few percent for a given time scale and amplitude/noise ratio. 
The scintillation decay characteristics were determined on a classical single photon method bench with a $22 \mathrm{Na}(1.6 \mathrm{MBq})$ radiation source. Besides spectrally unresolved decay time measurements, a Jobin Yvon H20 UVL monochromator was included in the bench for spectral analysis. The decay time curves obtained in this way were used to extract the radio-luminescence spectra, corrected for the spectral response of the R1668 Philips photomultiplier and monochromator used to detect the scintillation from the crystal. Due to the sharp decrease of quantum efficiency of the $\mathrm{PM}$, the luminescence above $600 \mathrm{~nm}$ is not detected in our measurements. The same set-up was used to measure the temperature dependence of scintillation decay parameters. For this purpose a commercially available TRG/TBT cryostat free of oil vapour, with a BT200/TBT temperature controller were included in the decay time measuring chain.

For the light yield (LY) measurements the samples were wrapped with a $12 \mu \mathrm{m}$ thick reflective sheet of aluminised mylar and optically coupled to a quartz window XP2020Q Philips PM by an optical grease 47V Rhodorsil from RhônePoulenc. The fluorescence produced by gamma rays from a 137Cs radioactive source is measured by the PM and the signal is processed by a shaping amplifier Borer type CERN N2620 and analysed on a Tracor-Northern TN-7200 multichannel analyser. The LY values obtained refer to the amount of light collected, i.e. extracted from the glass block and impinging on the photocathode of the photomultiplier. The samples used were large enough to fully contain the gamma energy. No attempt has been made to correct for sample shape or volume.

\subsection{Photoluminescence}

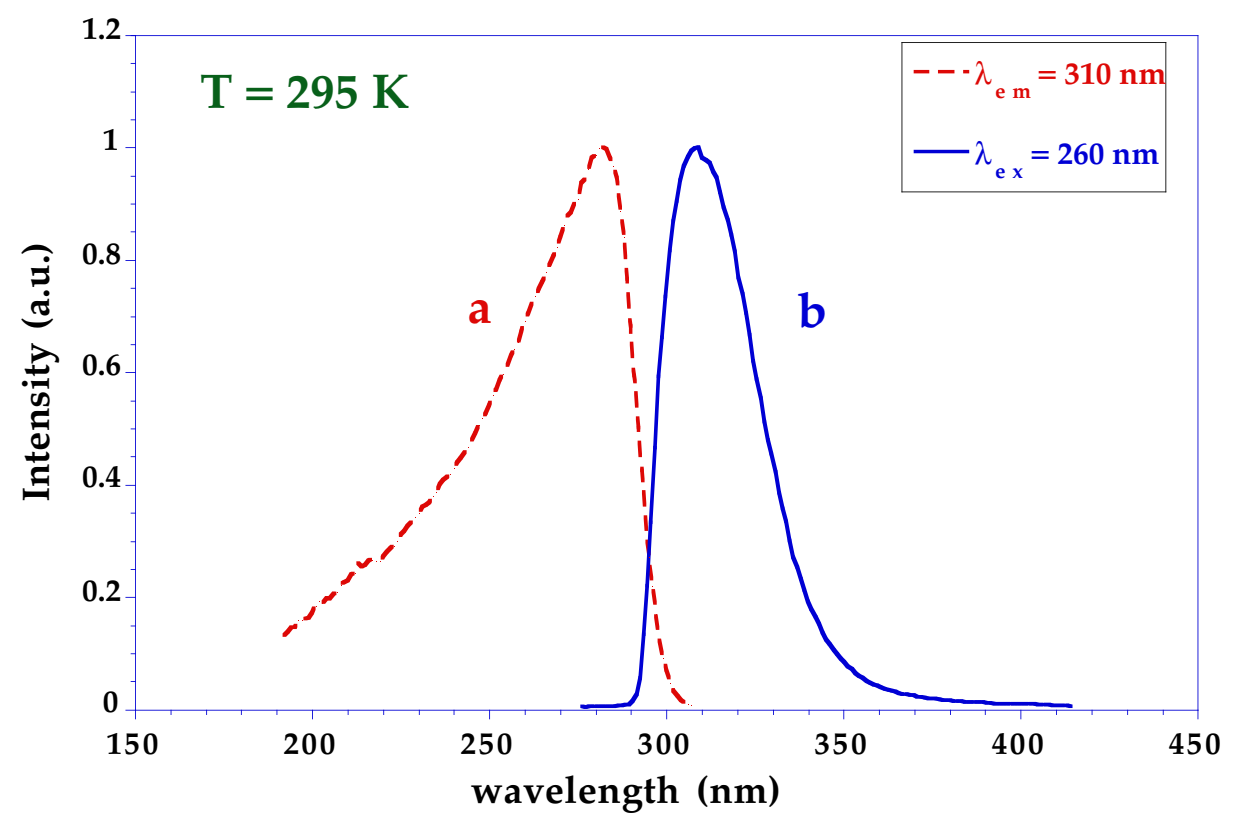

Fig. 4 Excitation (a) and emission (b) spectra of HFG:Ce glass

The room temperature (RT) excitation and emission spectra of HFG glass is given in Fig. 4, a and b, respectively. The peaks of the spectra are located close to those of $\mathrm{Ce}^{3+}$ ions in crystalline fluoride matrices at room temperature (RT) [6, 7]. The rather smooth character of excitation spectrum in Fig. 4(a) with respect to the 
structured $\mathrm{CeF}_{3}\left(\mathrm{LaF}_{3}: \mathrm{Ce}\right)$ one can be understood as a result of simultaneous excitation of many slightly non-equivalent $\mathrm{Ce}^{3+}$ sites in the glass matrix. The presence of this non-equivalent $\mathrm{Ce}^{3+}$ sites is proven by the dependence of the shape and position of $\mathrm{Ce}^{3+}$ emission spectra on the excitation wavelength (see Fig. 5).

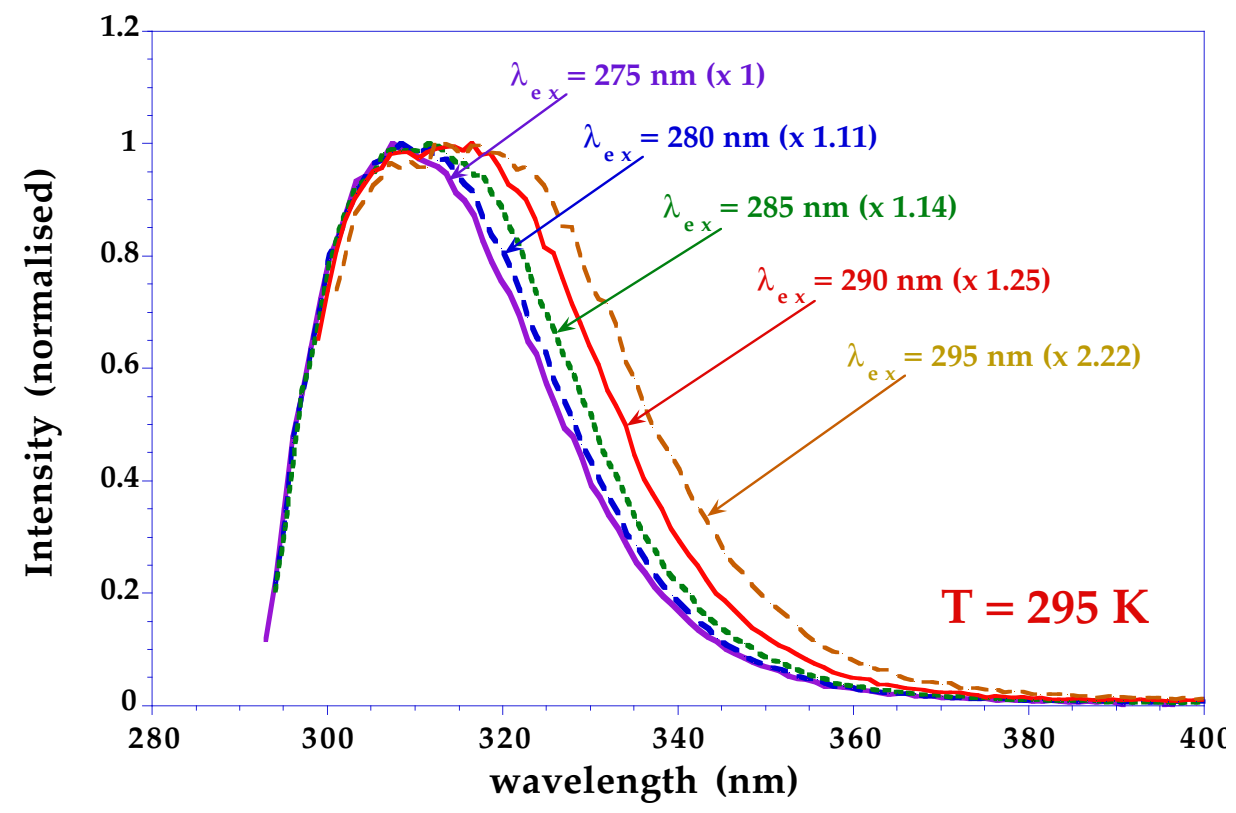

Fig. 5 Shift of emission peak for different excitation wavelengths in HFG:Ce glasses (normalisation coefficients are given in parenthesis)

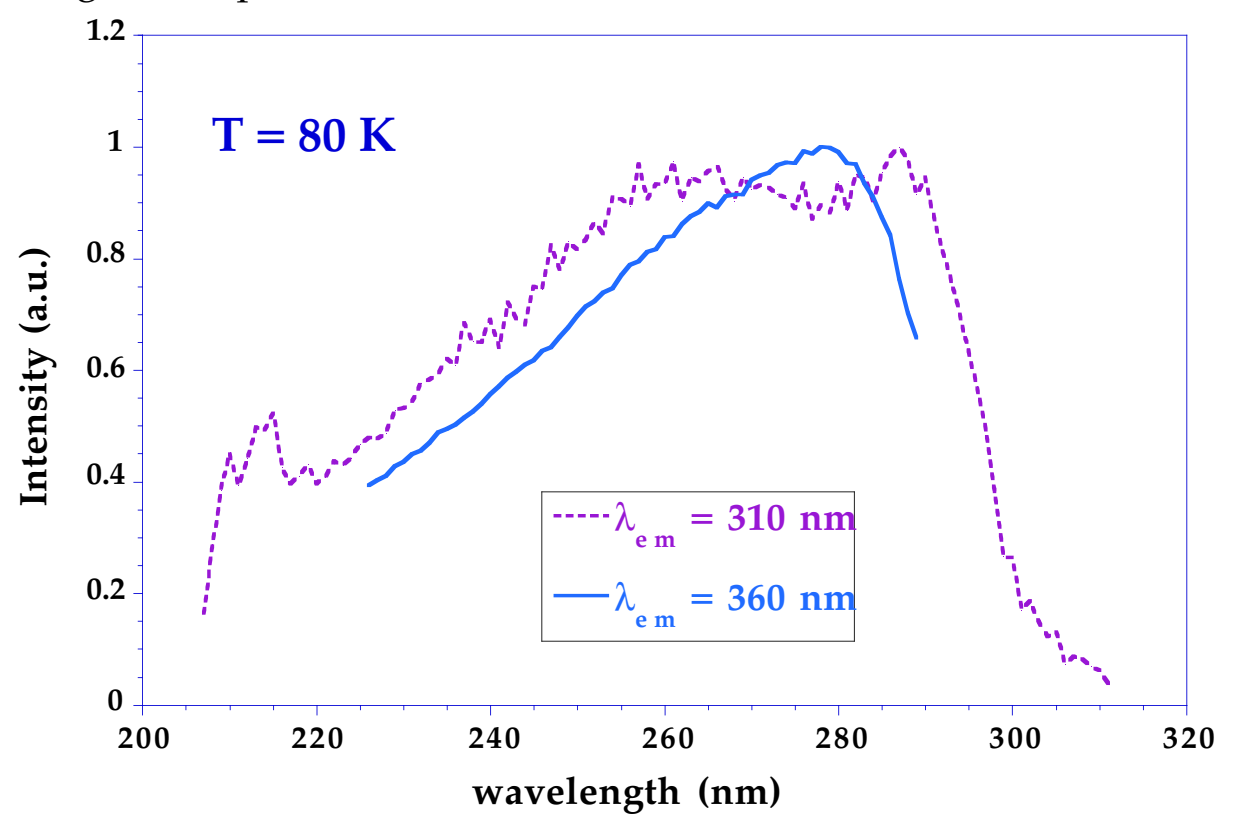

Fig. 6 Excitation spectrum of HFG:Ce glass

Furthermore, the excitation spectra for emission wavelength $310 \mathrm{~nm}$ (maximum of the emission) and $360 \mathrm{~nm}$ are given in Fig.6 at $80 \mathrm{~K}$. Emission at $360 \mathrm{~nm}$ is also excited at longer wavelengths with respect to the $310 \mathrm{~nm}$ excitation spectrum and a sign of competition between the centres emitting at these wavelengths can be derived from the shape of the spectra in the region $260-290 \mathrm{~nm}$. 


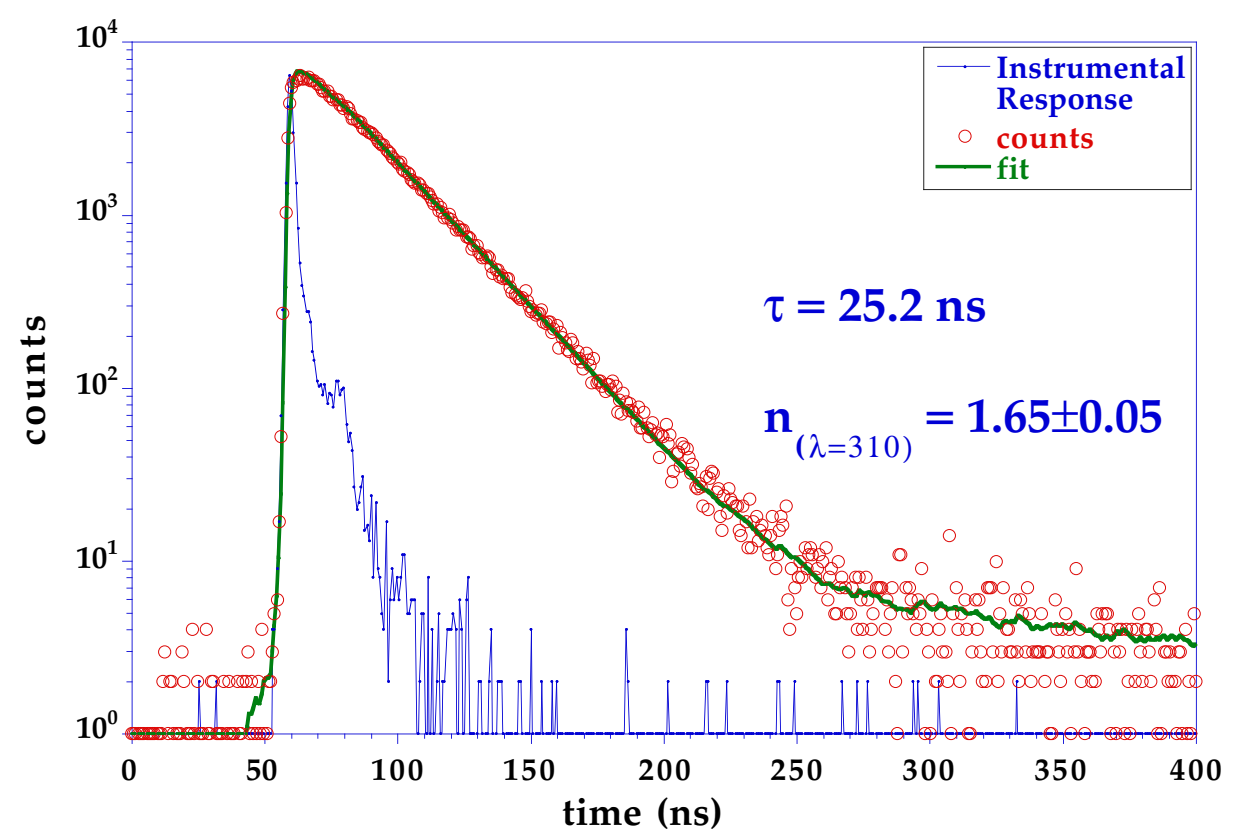

Fig. 7 Photoluminescence decay of HFG:Ce glass at room temperature $\left(\lambda_{\mathrm{ex}}=270 \mathrm{~nm} ; \lambda_{\mathrm{em}}=310 \mathrm{~nm}\right)$

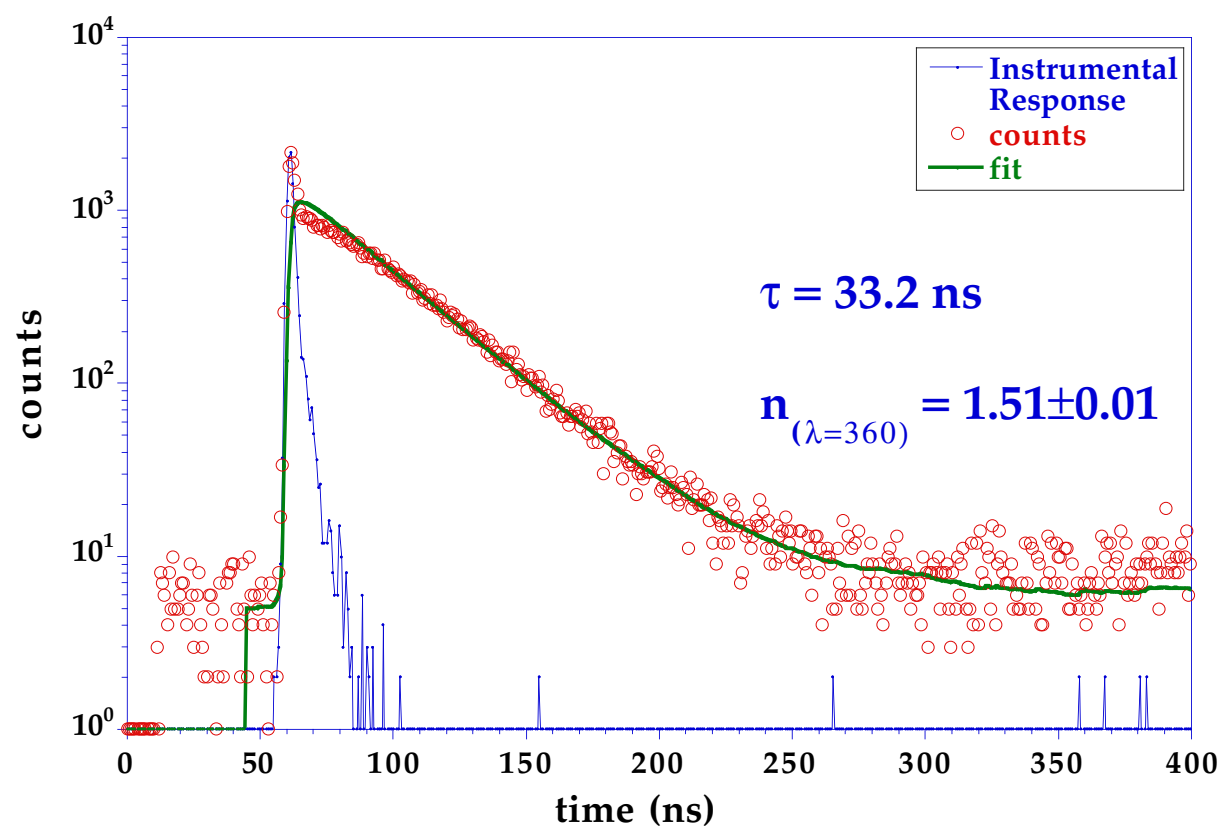

Fig. 8 Photoluminescence decay of HFG:Ce glass at room temperature $\left(\lambda_{\mathrm{ex}}=290 \mathrm{~nm} ; \lambda_{\mathrm{em}}=360 \mathrm{~nm}\right)$

In Fig.7, the photoluminescence decay at $310 \mathrm{~nm}$ is given at room temperature for an excitation at $270 \mathrm{~nm}$. Single exponential fit with a $25.2 \mathrm{~ns}$ decay time is in very good agreement with the data and close to the value found for $\mathrm{CeF}_{3}$ or $\mathrm{Ce}^{3+}$ ions in $\mathrm{LaF}_{3}$ matrix at the same emission wavelength (about $20 \mathrm{~ns}$ ) [7]. The fact that the decay of $\mathrm{Ce}^{3+}$ has a single exponential form even in a glassy matrix results from the small influence of the ion environment on the transition dipole moment from $\mathrm{Ce}^{3+}$ excited $5 \mathrm{~d}$ states (completely split by low site symmetry) to the ground $4 \mathrm{f}$ state of $\mathrm{Ce}^{3+}$ ions. Fig. 8 shows the decay of the emission at $360 \mathrm{~nm}$ obtained by excitation at 
the low energy tail of $\mathrm{Ce}^{3+}$ excitation spectrum. Apart from a small initial distortion, the decay can be well approximated by a single exponential with the decay time 33.2 ns. The lengthening of the decay time with increasing wavelength is in accordance with the general theory of radiative transitions in solids [8]. Indeed, since nonradiative desexcitation can be neglected in this case, the photoluminescence decay time $(\tau)$ is equal to the inverse of the Einstein coefficient ( $\left.A_{a b}\right)$ for spontaneous emission and for electric dipole transition we have:

$$
\frac{1}{\tau}=A_{a b} \propto n \cdot\left[\frac{(n+2)}{3}\right]^{2}
$$

where $\mathrm{n}$ is the refractive index of the material. Using the values given in this article for $\tau$ and $\mathrm{n}$ for $\lambda=310 \mathrm{~nm}$ and $\lambda=360 \mathrm{~nm}$ (see fig.7,8) one can verify that ( 3 ) is well satisfied.

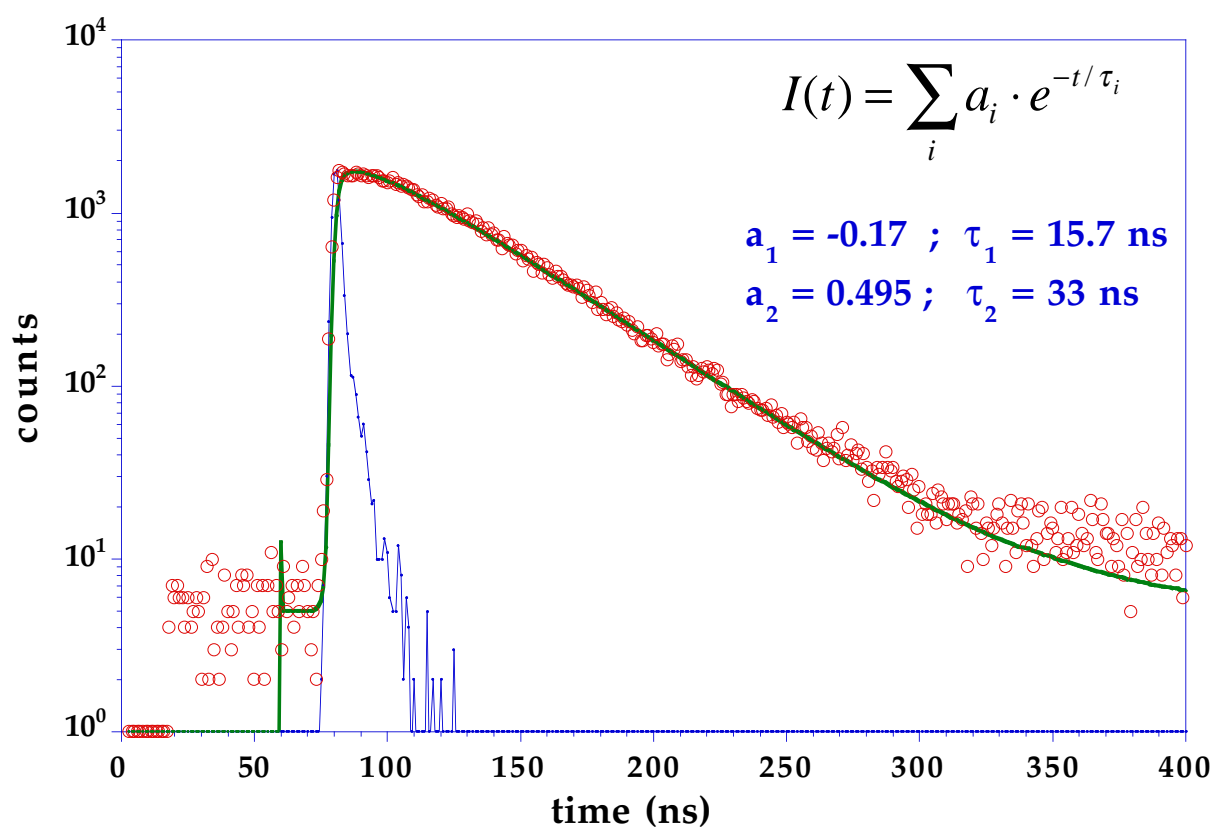

Fig. 9 Photoluminescence decay of HFG:Ce glass at room temperature $\left(\lambda_{\mathrm{ex}}=260 \mathrm{~nm} ; \lambda_{\mathrm{em}}=360 \mathrm{~nm}\right)$

If the decay curve is measured at the same emission wavelength $360 \mathrm{~nm}$, but under excitation at $260 \mathrm{~nm}$, there is a rising part in the decay curve and the decay has to be approximated by the difference of two exponentials (fig. 9). This situation strongly reminds the characteristics found for $\mathrm{Ce}^{3+}$ perturbed sites in $\mathrm{CeF}_{3}$, indicating an energy transfer from regular to perturbed sites.

The results found could be understood under the assumption that CeF3-like ordered phase is created in HFG glass matrix. The dimension of such aggregates is probably rather small, even in nanometer scale. However, it is very unlikely to find the same kind of quantum confinement effects (e.g. exciton superradiance, which may substantially shorten the observed decay time and enhance radiative efficiency at least at low temperatures [9]), because the exciton migration in $\mathrm{CeF}_{3}$ (if any) is phonon assisted at RT [10], i.e. slow and of incoherent character. Hence, true space limitation of coherent exciton motion in the aggregates, which is the basic 
assumption for enhanced quantum confinement effect, probably can not be achieved in this system.

\subsection{Radioluminescence}

Figure 10 shows the scintillation decay of a $\mathrm{HFG}(5 \% \mathrm{Ce})$ sample obtained for $511 \mathrm{keV} \gamma$-excitation. Unlike the photoluminescence decay, all of the several physically non equivalent $\mathrm{Ce}^{3+}$ sites with different energy levels are now excited at once. As a result the decay is no more described by a single exponential. Another typical feature is the presence of a very fast component which is probably due to the existence of local $\mathrm{CeF} 3$-like microphase where interaction of two close lying excited $\mathrm{Ce}^{3+}$ ions may occur [11] resulting in a strong quenching of luminescence. The decay curve is very well fitted by the sum of three exponentials but, for practical purposes the decay process is better described by considering the fraction of light contained within a given time interval. Integrating the curve, one finds the time dependence given in the inset of fig. 10 showing that $65 \%$ of the light is emitted in the first $30 \mathrm{~ns}$. The scintillation decay is not influenced by dopants like $\mathrm{NbO}_{2} \mathrm{~F}, \mathrm{NaPO}_{3} \mathrm{~F}, \mathrm{OH}^{-}$, $\mathrm{Mn}^{2+}[11,12]$.

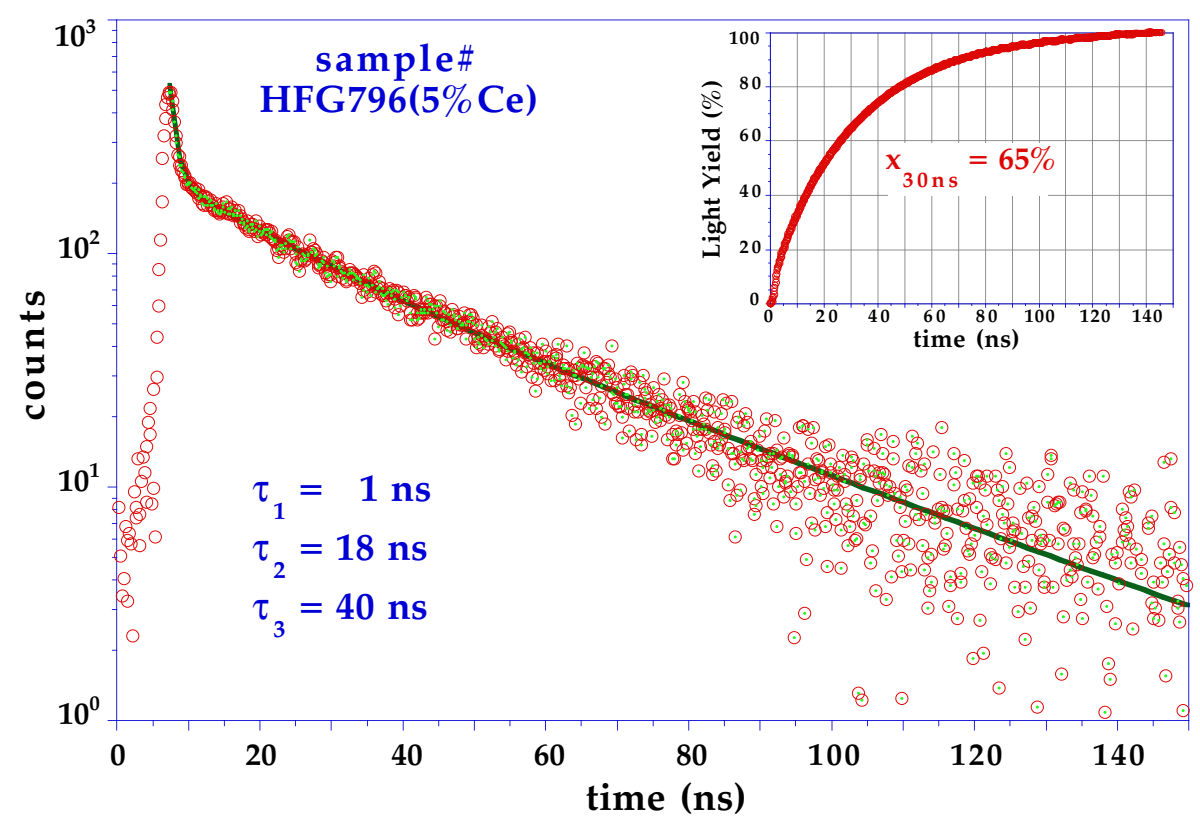

Fig.10 Scintillation decay spectrum for a $\operatorname{HFG}(5 \% \mathrm{Ce})$ sample.

In the inset is given the integral in time of the total emitted light

Since for high resolution experiments in HEP, the thermal stability is a crucial parameter, a careful study of temperature dependence of scintillation decay characteristics was made. Fig.11 gives the temperature dependence of scintillation decay time and relative contributions of the slow and fast components to the light yield. The fact that the contribution of the slow component in the total LY is increasing with temperature (fig. 11b) though both slow and fast decay time constants are decreasing (fig. 11a), is a sign that the decrease of the LY with increasing temperature (fig. 14) is not only due to a thermal quenching of the $\mathrm{Ce}^{3+}$ luminescence. Under gamma excitation, several recombination channels are active 
for free electrons and holes before they recombine radiatively (or create excitonic states and then decay).
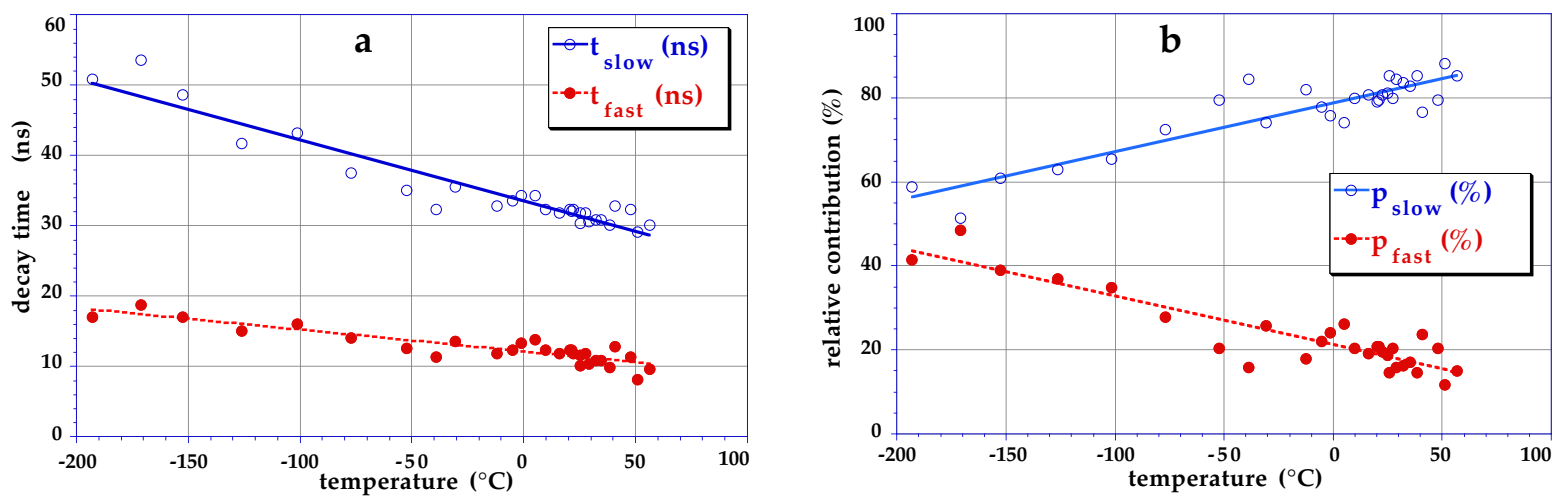

Fig.11 Temperature dependence of scintillation decay time (a) and relative contributions of the slow and fast components to the light yield (b)

For example, an increasing contribution of the diffusion of free carriers to the scintillation decay must be present at higher temperatures. Figure 12 gives the temperature dependence of the LY as well as of the temperature coefficient defined as:

$$
\alpha(\%)=100 \cdot(1 / L Y)_{20^{\circ} \mathrm{C}} \cdot \frac{d}{d T}(L Y)
$$

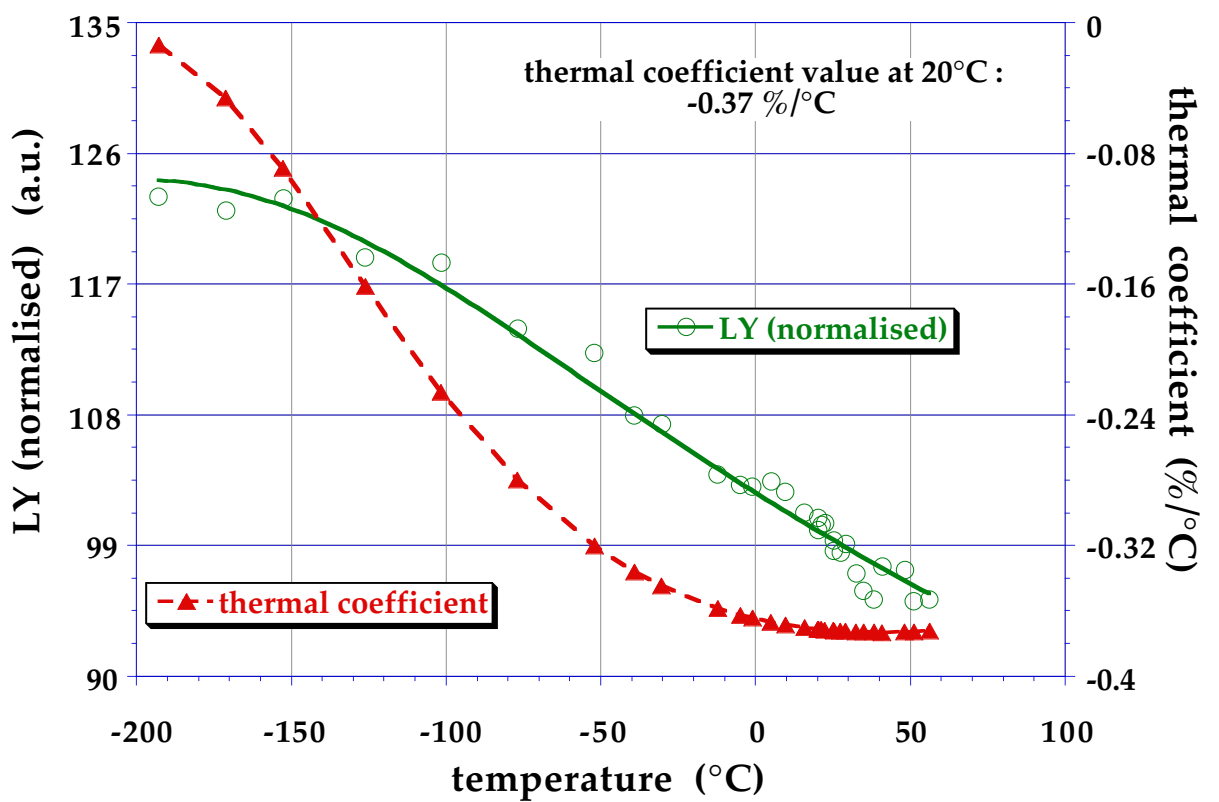

Fig.12 Temperature dependence of the light yield for $\mathrm{HFG}(5 \% \mathrm{Ce})$ glass scintillators

Fig.13 illustrates one of the main problems of Ce doped HFMG scintillators. In a HMFG host, the environment of $\mathrm{Ce}^{3+}$ ions doesn't have an unique configuration. It makes the values of both absorption and emission energy levels different from a site to another. This peculiarity of glassy environment, added to the fact that the Stokes shift in $\mathrm{CeF}_{3}$ is quite small, makes the reabsorption of scintillation light in $\mathrm{Ce}$ 
activated HMFG very probable. It explains the shift to $320 \mathrm{~nm}$ of the scintillation peak compared to the peak position of the photoluminescence spectrum $(310 \mathrm{~nm}$, fig.4). For $\gamma$-rays the excitation takes place in the bulk of the material and the weight
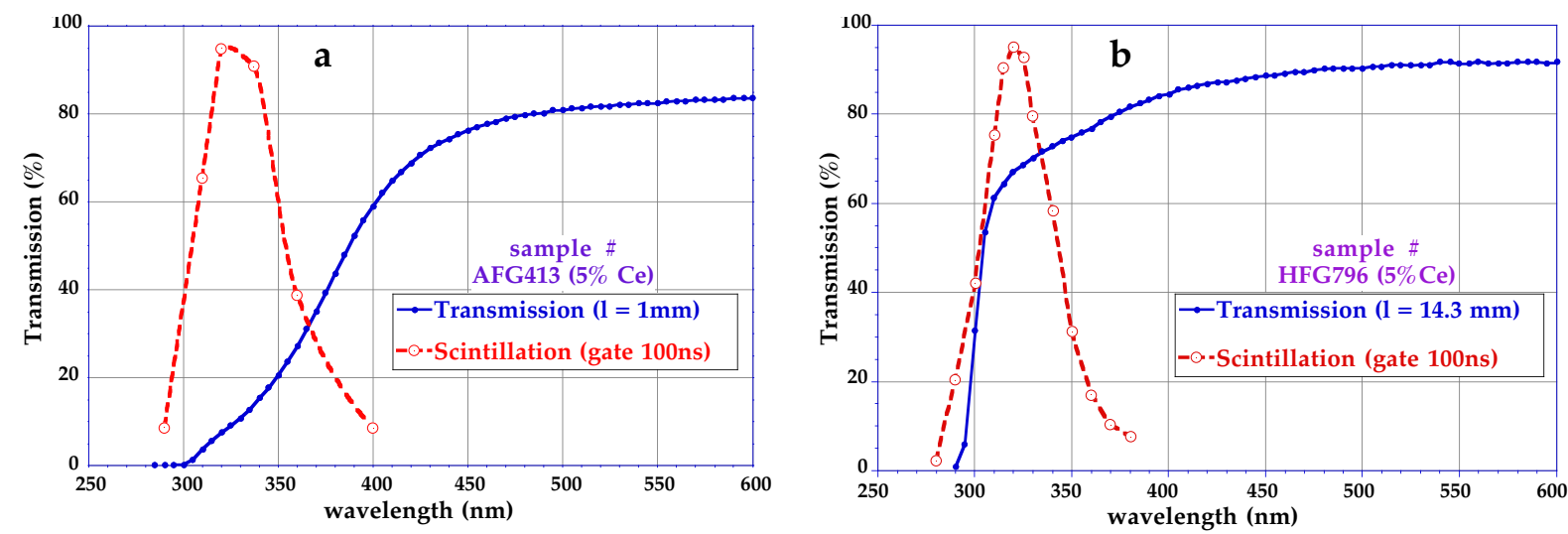

Fig.13 Transmission and radioluminescence (100 ns gate) spectra of AFG:Ce (a) and HFG:Ce (b) glasses

of "perturbed" sites in this case is very important since in a way all $\mathrm{Ce}^{3+}$ ions in a glassy environment are perturbed compared to normal $\mathrm{Ce}^{3+}$ sites in $\mathrm{CeF}_{3}$. In HFG:Ce glass, the effect discussed above is not as strong as in AFG:Ce glass and this is the main reason why the HFG:Ce glass was prefered. Nevertheless, the effect of reabsorption is present in large HFG:Ce ingots (fig.14).

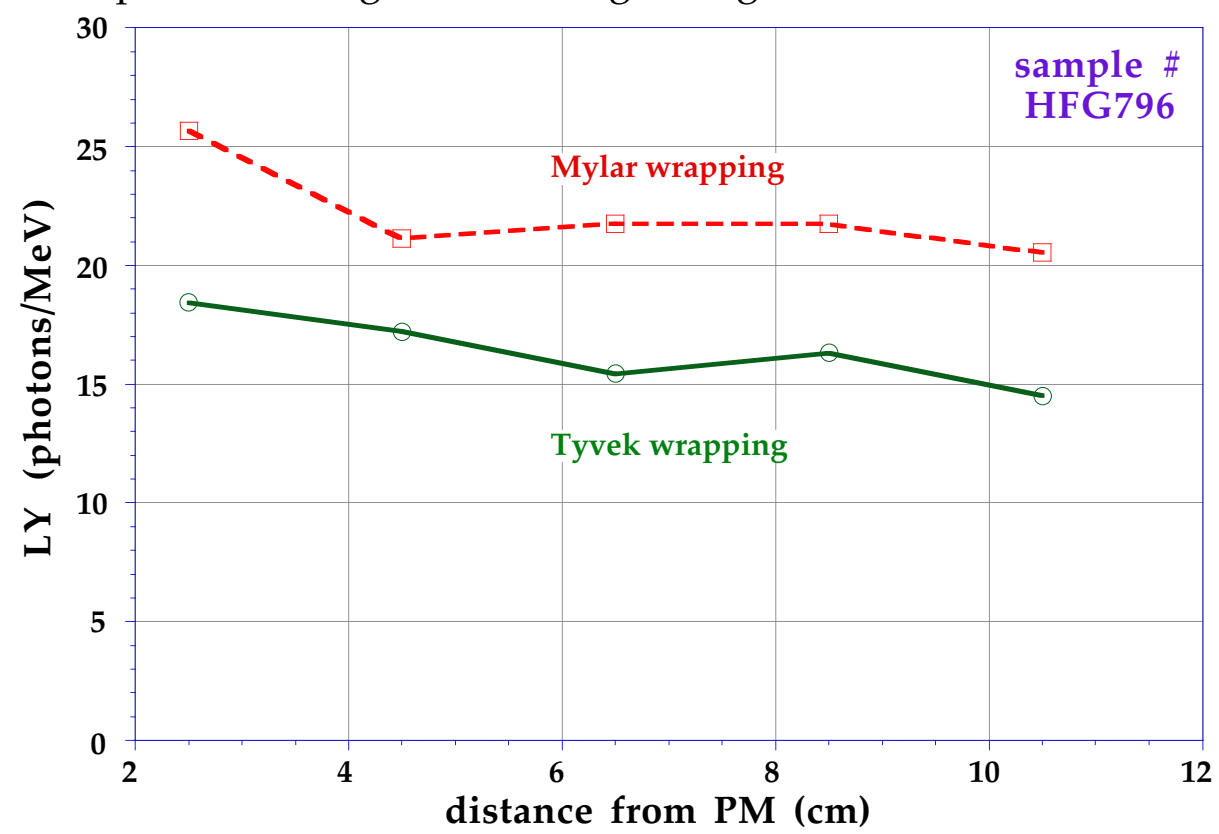

Fig.14 The scintillation yield of a HFG $(5 \%$ Ce $)$ glass ingot excited $\left(\mathrm{Co}^{60}\right)$ at various positions along its length

The light yield of Ce doped HFG was found to increase monotonously with cerium concentration up to the level of $10 \%$ which was the maximum possible without crystallisation. Above this value, the "noncrystallization" is hard to be mastered. Fig.15 gives the variation of the light yield with cerium fluoride concentration for HFG glasses. The influence of Mn codoping is also illustrated as a 
part of a study [11] of the influence of this dopant on the HFG:Ce scintillator characteristics.

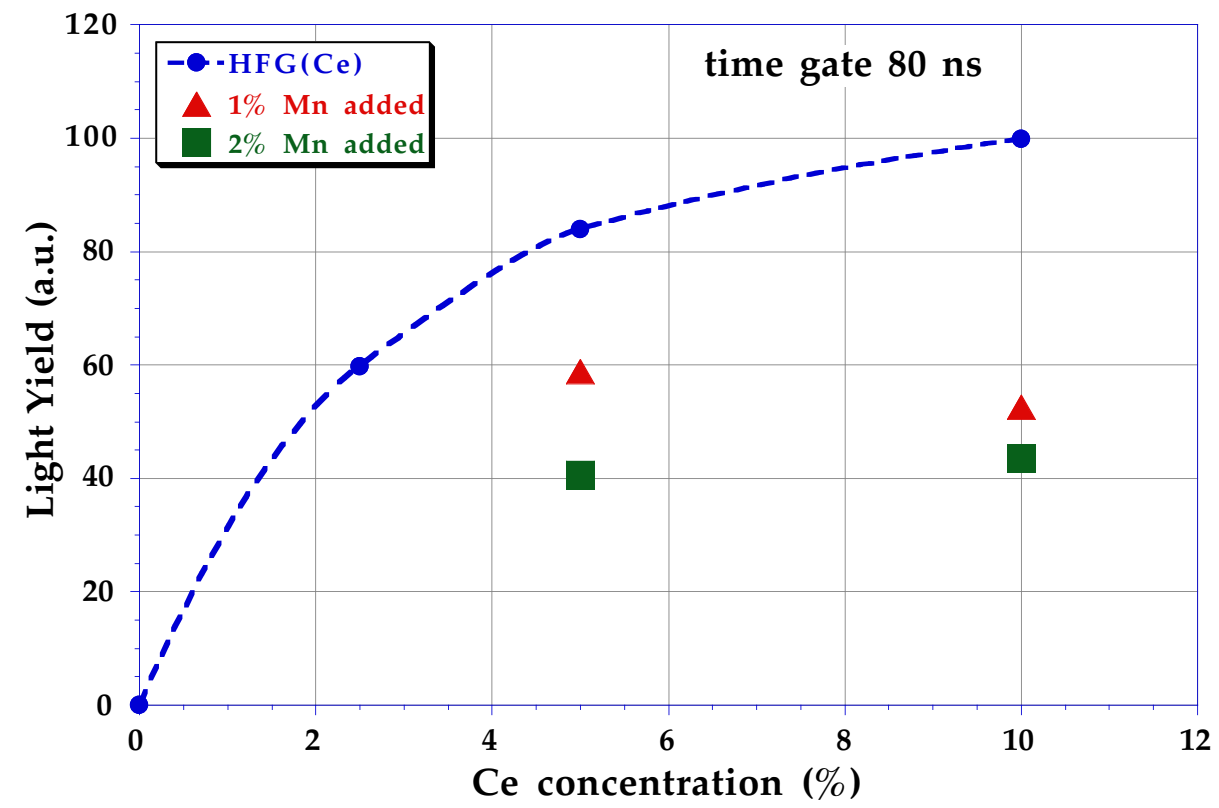

Fig. 15 Light yield evolution with Ce concentration in HFG glasses

\section{Radiation damage studies}

When HMFG scintillators are subject to irradiation, charge compensation processes must occur to balance the capture of electrons or holes by heterovalent ions. The new valence state can have energy levels such that absorption of photons in visible region occurs. This absorption saturates at a level dependent on the concentration of the component(s) responsible for the process. When after irradiation the temperature of the glass is raised these electronic defects can become unstable and recombine yielding thermoluminescence.

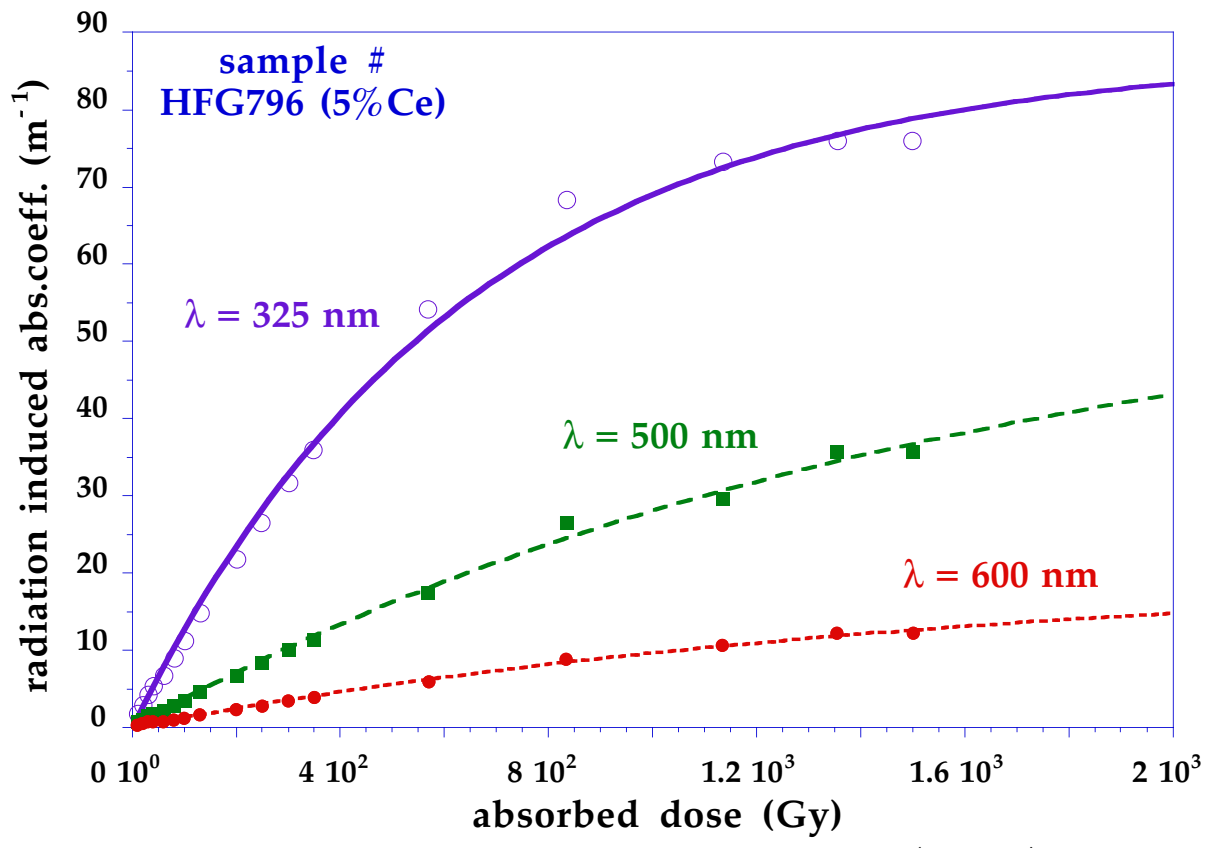

Fig. 16 Saturation of radiation damage in $\mathrm{HFG}(5 \% \mathrm{Ce})$ glass 
Several kinds of HMFG samples (Ce activated or not) were irradiated with the 60Co source (4400Ci) from the radiotherapy unit of Geneva Cantonal Hospital, with different radiation dose steps at a dose rate of $3 \mathrm{~Gy} / \mathrm{min}$. Optical transmission spectra before and after irradiation were recorded in the range of 200 to $700 \mathrm{~nm}$ on a spectrophotometer built at CERN, using a 150W Xenon lamp as a source and a JobinYvon H20UV monochromator with a resolution of $2 \mathrm{~nm}$. In order to characterise the radiation damage, the radiation induced absorption coefficient $\mu(\lambda)$ was defined as:

$$
\mu(\lambda)=\frac{1}{\mathrm{~d}} \cdot \ln \left(T_{0}(\lambda) / T(\lambda)\right)
$$

where $\quad \mathrm{d}$ : sample thickness

$\mathrm{T}_{0}$ : optical transmission before irradiation

$\mathrm{T}$ : optical transmission after irradiation

The radiation damage in Ce doped HFG is characterised by a broad unstructured absorption band peaking around $350-360 \mathrm{~nm}$. A saturation of the damage is reached for doses exceeding 1.5 - $2 \mathrm{kGy}$ (fig.16).

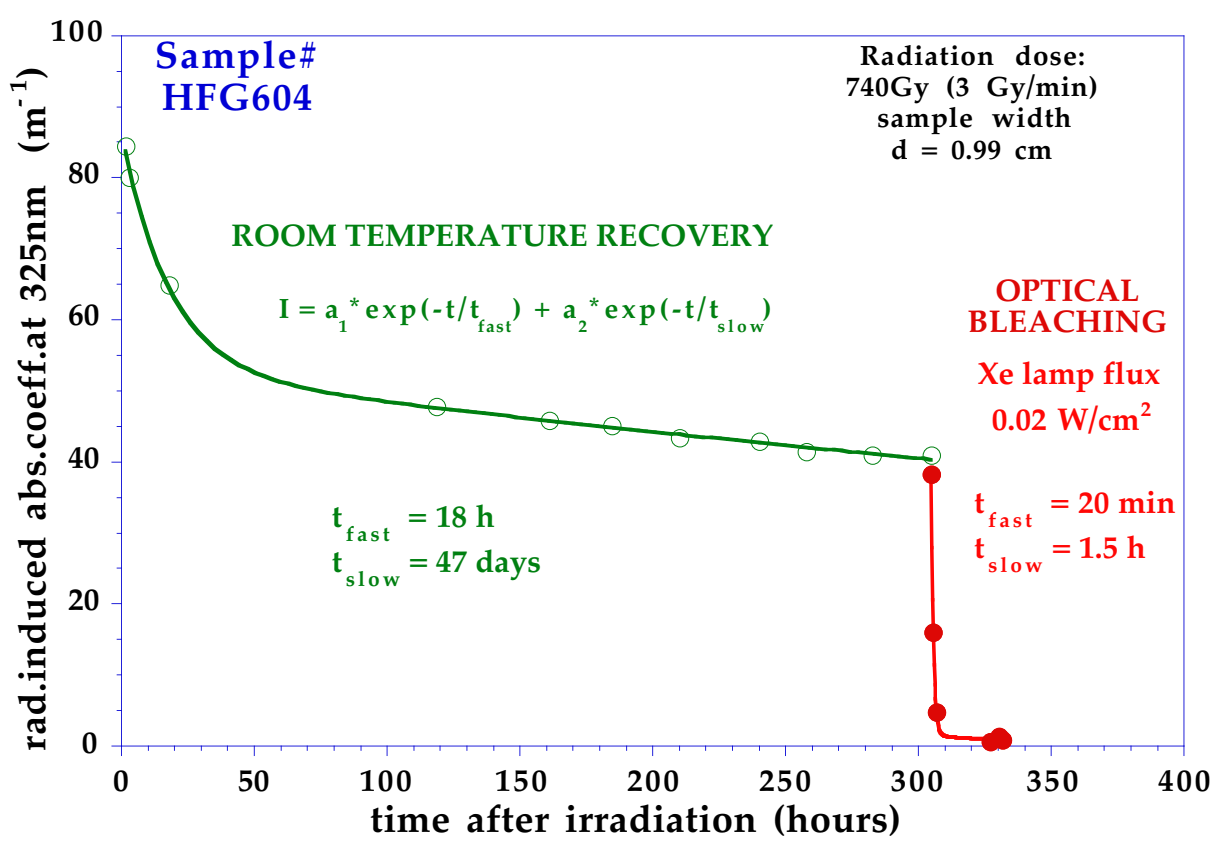

Fig. 17 Room temperature recovery and optical bleaching of radiation induced defects in $\mathrm{HFG}(5 \% \mathrm{Ce})$ glasses

The dose rate received by a scintillator is usually much lower than the one used in our tests. The estimated dose rate in the LHC environment for example, is evaluated at $10^{4} \mathrm{~Gy} /$ year $\approx 0.46 \mathrm{~Gy} / \mathrm{min}[14]$. This is why the effect of thermal annealing over a long period of time at room temperature has to be taken into account. Room temperature recovery was observed during one month on a HFG $(5 \% \mathrm{Ce})$ sample after $740 \mathrm{~Gy}$ irradiation. The recovery process is well fitted by a double exponential (fig.17) with recovery time constants of $18 \mathrm{~h}$ and 47 days. 
After the saturation of the recovery the photoinduced bleaching process was studied using a $150 \mathrm{~W}$ Xe lamp. A complete recovery of the transmission is observed after an $8 \mathrm{~h}$ exposure to a light flux of $\approx 0.02 \mathrm{~W} / \mathrm{cm}^{2}$.

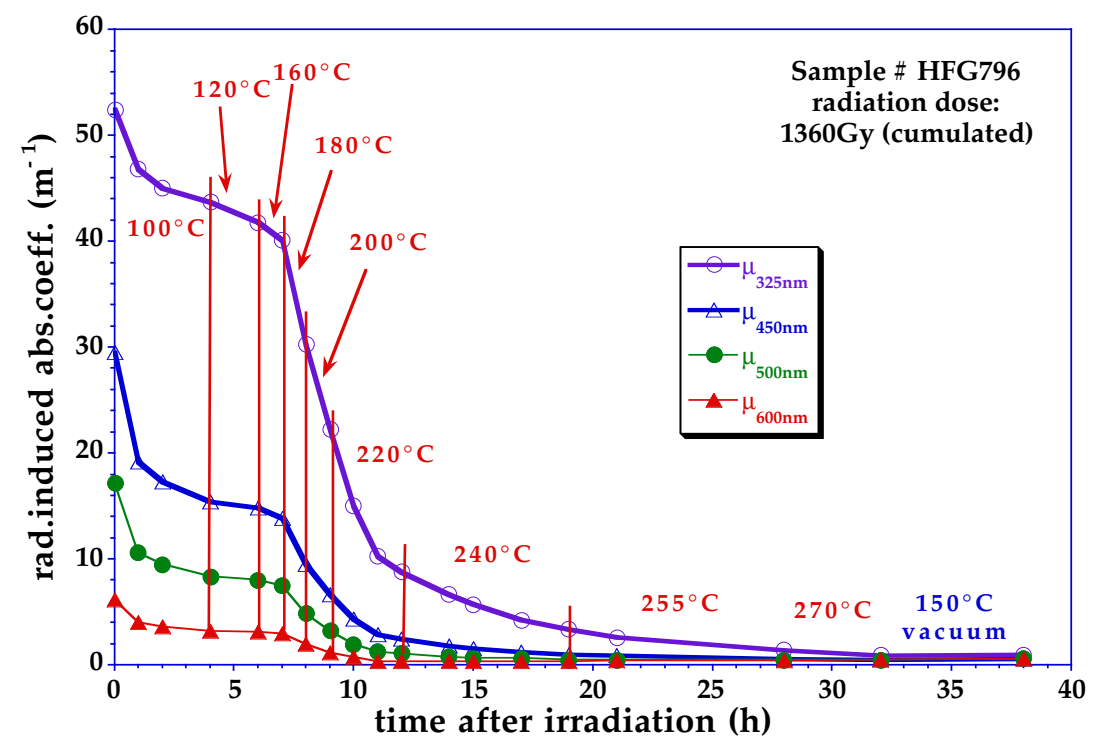

Fig.18 Thermal annealing of radiation induced defects in $\mathrm{HFG}(5 \% \mathrm{Ce})$ glasses

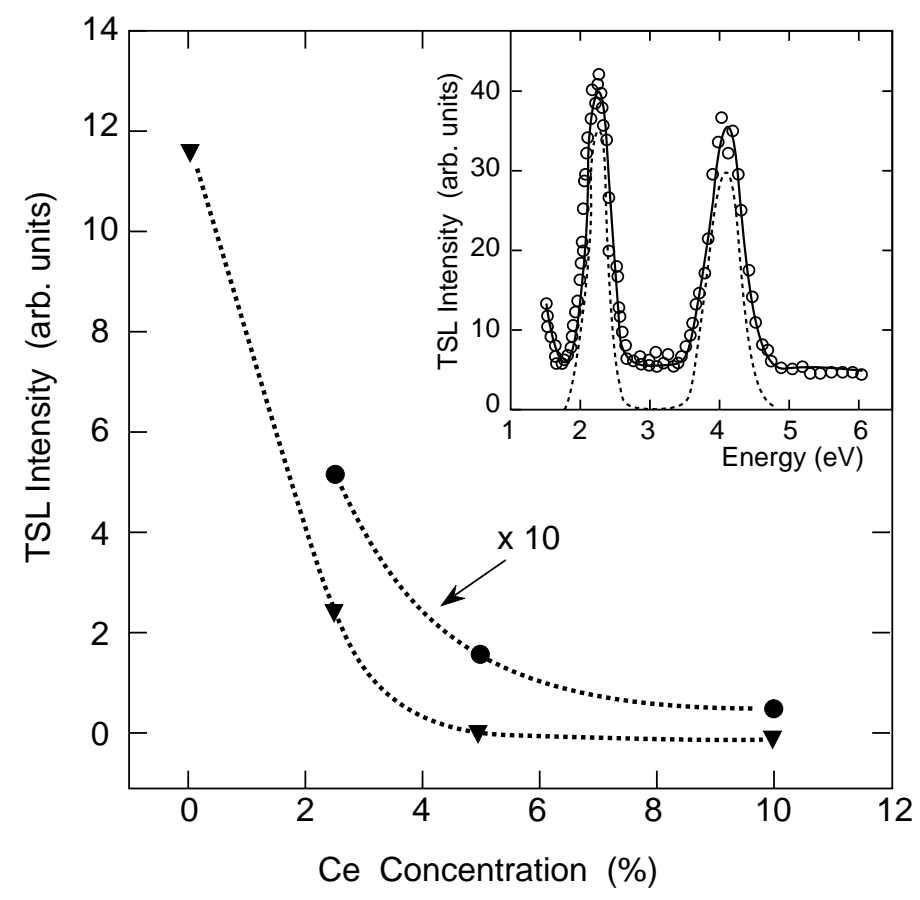

Fig.19 Intensities of the Thermally stimulated luminescence (TSL) bands as a function of cerium dopant concentration for a $5 \times 10^{4} \mathrm{~Gy}$ X-ray irradiation dose. Circles indicate the $300 \mathrm{~nm}$ band and triangles the $552 \mathrm{~nm}$ band. The inset shows the energy spectrum of the TSL, with deconvolution into gaussian components. Circles represent the experimental data, the full line the calculated spectrum and dashed line the gaussian components. Integration has been performed in the $200-300{ }^{\circ} \mathrm{C}$ region, in which the intensities of the two bands are similar [13]. 
The thermal bleaching of radiation induced absorption centres was also studied both in normal atmosphere and in vacuum. Fig.18 gives the bleaching effect observed for different annealing conditions applied when the fast part of the room temperature recovery was over. No improvement of the radiation hardness or of the spontaneous recovery is obtained when different dopants $\left(\mathrm{NbO}_{2} \mathrm{~F}, \mathrm{NaPO}_{3} \mathrm{~F}, \mathrm{OH}-\right.$, $\mathrm{Mn}^{2+}$ ) are used in the casting of HFG:Ce glass [10].

Thermally stimulated luminescence (TSL) glow curves obtained on HFG:Ce and Mn co-doped HFG:Ce samples are characterised by broad and unresolved structures, extending in the whole temperature range from $20^{\circ} \mathrm{C}$ to $350^{\circ} \mathrm{C}$ [13]. This calls for the presence of a complex distribution of trap depths, as can be expected in an amorphous and composite host matrix. The emission spectra of TSL, displayed in the inset of fig. 19, revealed the presence of two bands centred at 300 and $550 \mathrm{~nm}$ and attributed to Ce and $\mathrm{Mn}$ ions respectively. $\mathrm{Mn}$ co-doping up to $2 \%$ produced a strong enhancement of the TSL intensity, suggesting that this dopant ion is very efficient in trapping free electrons and holes followed by radiative de-excitation [13]. The most important result of TSL measurements is that they evidence the strong quenching effect of Ce on the TSL signal intensity (see fig.19). As it was pointed out in [10], cerium has the ability to enhance the radiation hardness of a host matrix. In fact, $\mathrm{Ce}^{3+}$, by loosing its $4 \mathrm{f}$ electron, prevents the formation of $\mathrm{V}$-centre like defects; similarly, by capturing electrons which would be trapped by anion vacancies, $\mathrm{Ce}^{4+}$ can prevent the formation of F-centre like defects. It gives one more argument for a $\mathrm{CeF}_{3}$ concentration in HFG as high as the specific constraints imposed by glass casting technology permits.

\section{Conclusions}

The method of casting large size $\left(15 \times 3 \times 3 \mathrm{~cm}^{3}\right) \mathrm{HFG}$ :Ce glass pieces having a good optical quality is well mastered, and the scintillation mechanism in this system is well understood.

The observed emission properties of $\mathrm{Ce}^{3+}$ ions in glassy HFG matrices are in many aspects similar to what was observed in $\mathrm{CeF}_{3}$ or $\mathrm{Ce}^{3+}$ doped $\mathrm{LaF}_{3}$ crystalline systems. The glassy matrix influences mainly the position of the excited state $5 \mathrm{~d}$ levels (smooth character of the excitation spectra and enlarged FWHM of the emission spectrum with respect to the mentioned crystal systems), while the transition dipole moment associated with the radiative transition is rather insensitive to the surrounding symmetry, which is always very low. Possible occurrence of "perturbed $\mathrm{Ce}^{3+}$ sites" similar to those found in $\mathrm{CeF}_{3}$ single crystals, supports the hypothesis about creation of $\mathrm{CeF}_{3}$-like aggregates in HFG glassy matrices, which might be very similar to the creation of semiconductor CdSe, CdTe or other similar aggregates in glass matrices.

The relatively poor radiation hardness of HFG:Ce still remains the main impediment in using it as a scintillator in HEP experiments where high radiation doses are expected. The complete recovery of initial transmission by optical annealing of irradiation damaged glass samples, might be a solution to this problem.

Ce ability to increase both the light yield and the radiation hardness of fluoride glass scintillators is a strong stimulus in the research activity for carrying out glass casting technologies which allow higher Ce concentration without devitrification. 


\section{References}

[1] Heavy Scintillators for Scientific and Industrial Applications, Proceedings of the "Crystal 2000" Intenational workshop, Sept. 22 - 26, 1992, Chamonix, France, Ed. Frontiers (1993)

[2] MRS Proceedings Series (Scintillators and Phosphors), vol. 348 (1994)

[3] Proceedings of the International Conference on Inorganic Scintillators and Their Applications, "SCINT95", Aug.28-Sept.1, 1995, Delft, The Netherlads, Delft University Press (1995)

[4] CERN/DRDC/93-31, RD-18/Status Report, 03 September 1993

[5] I.Dafinei, E. Auffray, P.Lecoq, M.Schneegans: MRS Proceedings Series (Scintillators and Phosphors), vol. 348,p.217 (1994).

[6] M.Nikl, J.A.Mares, E.Mihokova, A.Beitlerova, K.Blazek, J.Jindra: Sol. St. Comm. 87, 185 (1993).

[7] C.Pedrini et al., J.Phys.:Condens. Matter 4, 5461 (1992)

[8] B.Henderson, G.F.Inbush, "Optical Spectroscopy of Inorganic Solids, Clarendon Press, Oxford (1989)

[9] M.Nikl, K.Nitsch, I.Dafinei, P.Lecoq, G.P.Pazzi, P.Fabeni, M.Gurioli: MRS Proceedings Series (Scintillators and Phosphors), vol. 348,p.115(1994).

[10] M. Nikl, C. Pedrini: Sol.St.Comm. 90, 155 (1994).

[11] M.Nikl et all, J.Phys.: Condens. Matter 7, 6355 (1995)

[12] I.Dafinei "General review of glass scintillators at CERN" 16th Crystal Clear Collaboration meeting, Institute of Physical Chemistry, Prague, Czek Republic, October 17 - 19, 1994

[13] M. Martini, F. Meinardi, A. Vedda, I. Dafinei, P. Lecoq, M. Nikl, "Ce doped hafnate scintillating glasses: thermally stimulated luminescence and photoluminescence", Presented at the VIII Int.Conf.on Rad.Eff.in Insulators, Sep.11 - 15, Catania, Italy (to be published in Nucl.Instrumand Meth.)

[14] CMS Technical Proposal, CERN/LHCC 94-38, LHCC/P1, 15 December 1994 